\title{
Promoted delivery of salinomycin sodium to lung cancer cells by dual targeting PLGA hybrid nanoparticles
}

\author{
JIE ZHOU ${ }^{1}$, JIN SUN ${ }^{2}$, HUAIWEN CHEN ${ }^{3}$ and QING PENG ${ }^{1}$ \\ ${ }^{1}$ Department of Pulmonary Medicine, Minhang Hospital, Zhongshan Hospital, Fudan University, Shanghai 201199; \\ ${ }^{2}$ Department of Pharmacy, The Naval Medical University; ${ }^{3}$ Center of Clinical and Translational Medicine, \\ Shanghai Changhai Hospital, The Naval Medical University, Shanghai 200433, P.R. China
}

Received March 28, 2018; Accepted June 5, 2018

DOI: $10.3892 /$ ijo.2018.4474

\begin{abstract}
As the leading cause of cancer-associated mortality worldwide, lung cancer is often associated with therapy failure and decreases in survival; these factors are often attributed to lung cancer-initiating cells (CICs). In addition, sufficient evidence has suggested that simultaneous targeting of CICs, together with cancer cells, is critical for the achievement of preferable therapeutic efficacy, due to the spontaneous conversion between CICs and cancer cells. Salinomycin sodium (SS) is an antibacterial therapeutic agent that exerts potent activity against CICs in various types of cancer, including lung cancer. The present study generated SS lipid-polymer hybrid nanoparticles (NPs) with cluster of differentiation (CD)133 and epidermal growth factor receptor (EGFR) antibodies (CD133/EGFR SS NPs) for the simultaneous treatment of lung CICs and cancer cells. The activity of CD133/EGFR SS NPs was analyzed using cytotoxicity and tumorsphere formation assays, flow cytometry, and an in vivo anticancer assay in mice bearing lung cancer xenografts. The results revealed that CD133/EGFR SS NPs effectively promoted SS delivery to lung CICs and cancer cells, achieving superior therapeutic effects compared with non-targeted NPs or NPs with a single antibody. Furthermore, CD133/EGFR SS NPs exhibited the best efficacy in inhibiting tumor growth compared with the control agents in lung cancer-bearing mice. In conclusion, CD133/EGFR SS NPs may be capable of efficiently targeting and treating lung CICs together with cancer cells, and may represent an effective treatment for lung cancer.
\end{abstract}

\section{Introduction}

Lung cancer is the primary cause of cancer-associated mortality worldwide, and in 2017 it was also the primary cause

Correspondence to: Dr Qing Peng, Department of Pulmonary Medicine, Minhang Hospital, Zhongshan Hospital, Fudan University, 170 Xinsong Road, Shanghai 201199, P.R. China

E-mail: pengqing19810517@163.com

Key words: cancer-initiating cells, dual targeting, lung cancer, CD133, EGFR of cancer-associated death in the United States of America (1). Furthermore, in 2015, lung cancer in China was the leading cause of cancer-associated mortality in men $>75$ years old (2). Therefore, effective lung cancer therapy is urgently required for the improvement of public health. Although progress has been made in lung cancer therapy, treatment failure and decreases in the survival of patients with lung cancer is attributed to the metastasis and recurrence of lung cancer $(3,4)$. One of the crucial causes of metastasis and recurrence of lung cancer are lung cancer-initiating cells (CICs) (3-5); therefore, the elimination of lung CICs may contribute to the cure of lung cancer. Cluster of differentiation (CD)133 is a marker of CICs in various types of cancer, including lung cancer $(5,6)$. Bertolini et al demonstrated that $\mathrm{CD}_{133^{+}}$lung cancer cells display stronger self-renewal capabilities and induce more severe in vivo tumorigenicity compared with CD133- lung cancer cells (6).

Numerous studies have proposed that differentiated cancer cells have the ability to be converted into CICs (7-9). To obtain improved cancer therapeutic efficacy, several combination strategies that target both CICs and non-CICs have recently been developed $(10,11)$. Gong et al developed salinomycin sodium (SS) and doxorubicin-loaded liposomes to eliminate both liver CICs and cancer cells, and demonstrated that this combination therapy is superior to single therapy with SS or doxorubicin (10). Therefore, the eradication of lung CICs, together with cancer cells, is expected to obtain superior therapeutic efficacy, compared with targeting only CD133+ lung CICs.

$\mathrm{SS}$ is an antibacterial therapeutic agent that exerts potent activity against CICs in various types of cancer, including lung cancer (10-12). The underlying mechanisms be which SS targets CICs include inhibition of the Wnt pathway and induction of apoptosis (13). Notably, SS exerts marked cytotoxic effects against common lung and prostate cancer cells $(14,15)$. Therefore, SS represents a promising candidate drug that may combat lung CICs together with cancer cells. Nevertheless, the aqueous solubility of SS is poor; therefore, researchers have developed SS nanoparticles (NPs) to facilitate the preclinical application of SS in cancer therapy (10-14). Lipid-polymer hybrid NPs of biodegradable polymers and lipids represent superior candidate drug delivery systems, since they combine the advantages of liposomes and polymer 
NPs $(16,17)$. Liposomes are characterized by superior biocompatibility and easy modification of hydrophilic polymers [for example, poly(ethylene glycol) (PEG)] and targeting molecules (for example, antibodies, peptides and aptamers) $(18,19)$. The advantages of polymer NPs [for example, poly(lactide-coglycolide) acid (PLGA), which is the most used polymer] include controlled and sustained release, high drug loading and superior stability $(16,17)$. Therefore, the strengths of lipidpolymer hybrid NPs include their superior biocompatibility, modification, controlled and sustained release, stability and drug loading (16).

To promote the delivery of chemotherapy drugs to cancer cells, considerable interest has been paid to antibody-targeted NPs, which could obtain targeted cancer therapy (18-20). It is well known that antibody-targeted NPs have improved the therapeutic effect of chemotherapy in various types of cancer (19). It has also been reported that epidermal growth factor receptor (EGFR) is abundantly expressed in various cancer types, including lung cancer $(21,22)$. Furthermore, amplification of EGFR is a typical genetic aberration associated with lung cancer, thus suggesting that EGFR may be a promising therapeutic target for the treatment of lung cancer $(21,22)$. Several studies have developed NPs with EGFR antibodies to target cancer $(23,24)$. The present study hypothesized that, due to overexpression of EGFR in lung cancer, a significant portion of CD133- lung cancer cells may abundantly express EGFR, making it possible to target CD133- lung cancer cells by targeting EGFR. Since targeting CD133+ lung CICs could be realized by the conjugation of a CD133 antibody to NPs, it was proposed that NPs coupled with CD133 and EGFR antibodies may target lung CICs as well as cancer cells. Furthermore, the targeting of two antigens could enhance antigen density, and this increase in antigen density may result in increased cellular delivery of drugs $(25,26)$.

To target lung CICs together with cancer cells, the present study generated SS lipid-PLGA hybrid NPs with CD133 and EGFR antibodies (CD133/EGFR SS NPs). The characteristics, and targeting and therapeutic effects of CD133/EGFR SS NPs towards lung cancer were investigated, and the in vivo antitumor activity of CD133/EGFR SS NPs was examined in lung cancer-bearing mice.

\section{Materials and methods}

Materials. Lipids, including 1,2-distearoyl-sn-glycero-3-phosphoethanolamine- $\mathrm{N}$-[maleimide(PEG)-2000](DSPE-PEG-Mal), phosphatidylcholine and cholesterol were provided by Avanti Polar Lipids (Alabaster, AL, USA). PLGA (50:50, 40-75 kDa), polyvinyl alcohol (PVA, 30-70 kDa), coumarin 6, 2-iminothiolane (Traut's reagent), SS and organic reagents were purchased from Sigma-Aldrich (Merck KGaA, Darmstadt, Germany). EGFR (cat. no. MAB1095-500) and CD133 antibodies (cat. no. MAB11331) were obtained from R\&D Systems, Inc. (Minneapolis, MN, USA), and EGFR and CD133 Fab' were obtained according to our previous protocol (16). The Pierce Bicinchoninic Acid (BCA) Protein Assay kit, Roswell Park Memorial Institute 1640 (RPMI-1640) medium and fetal bovine serum (FBS) were purchased from Thermo Fisher Scientific, Inc. (Waltham, MA, USA). PerCP-Cy5.5 anti-EGFR antibodies (cat. no. sc-120 PCPC5) were obtained from Santa
Cruz Biotechnology, Inc. (Dallas, TX, USA). Phycoerythrin (PE)-CD133 antibodies (cat. no. 130080801) and the CD133 MicroBead kit (cat. no. 130-050-801) were provided by Miltenyi Biotec Technology \& Trading (Shanghai) Co., Ltd. (Shanghai, China).

Lung cancer cell lines culture. The human lung cancer cell lines, A549 and H460, were purchased from American Type Culture Collection (Manassas, VA, USA), and were cultured in RPMI-1640 medium supplemented with $2 \mathrm{mM} \mathrm{L}$-glutamine and $10 \%$ FBS. Lung cancer cells were cultured in a humidified atmosphere containing $5 \% \mathrm{CO}_{2}$ at $37^{\circ} \mathrm{C}$.

Antigen (EGFR and CD133) expression in lung cancer cell lines. Double-staining flow cytometry was conducted to analyze the expression of EGFR and CD133 in the lung cancer cell lines. Briefly, the lung cancer cells were dissociated into single cells, and the dissociated cells were incubated with PE-CD133 and PerCP-Cy5.5 anti-EGFR antibodies $(1 \mu \mathrm{g} / \mathrm{ml})$ diluted in $1 \% \mathrm{FBS}$ for $0.5 \mathrm{~h}$ at $4^{\circ} \mathrm{C}$. Subsequently, the cells were washed to remove unconjugated antibodies. Finally, the washed cells were suspended in PBS and a FACSCalibur flow cytometer (BD Biosciences, Franklin Lakes, NJ, USA) was used to analyze the proportion of positively stained cells. The data were analyzed using FlowJo (version 10; FlowJo LLC, Ashland, OR, USA).

Magnetic cell sorting-based separation of $\mathrm{CD} 133^{+}$cells. The separation of $\mathrm{CD} 33^{+}$cells from the lung cancer cells was conducted according to the protocol provided by the CD133 MicroBead kit [Miltenyi Biotec Technology \& Trading (Shanghai) Co., Ltd.]. A FACSCalibur flow cytometer was used to analyze the proportion of positively stained cells, as aforementioned.

Preparation of lipid-PLGA hybrid NPs. PLGA NPs were prepared according to the emulsion-solvent evaporation procedure. Briefly, $0.5 \mathrm{mg} \mathrm{SS}$ and $5 \mathrm{mg}$ PLGA were completely dissolved in acetone to form the oil phase. The oil solution was injected into 2\% PVA solution, followed by homogenization. Subsequently, the mini-emulsion was poured into $0.2 \%$ PVA solution, and quickly mixed for $6 \mathrm{~h}$ to remove any remaining acetone by evaporation; the NPs were recovered using ultracentrifugation $(80,000 \mathrm{x} \mathrm{g})$ for $0.5 \mathrm{~h}$ at $25^{\circ} \mathrm{C}$. Concurrently, a lipid film composed of phosphatidylcholine, DSPE-PEG-Mal and cholesterol (57:3:40 molar ratio) was formed in a round bottom flask using a vacuum rotary evaporator. Once the lipid film was formed, the prepared NPs were added to hydrate the film. A hand-held extruder (Avanti Polar Lipids) with $200 \mathrm{~nm}$ membranes was adopted to extrude the obtained lipid-polymer suspension to create small and homogeneous NPs. The resultant lipid-polymer NPs were washed by centrifugation $(2,000 \mathrm{x} \mathrm{g})$ with Amicon centrifugal filters [molecular weight cut-off (MWCO) $100 \mathrm{kDa}$; EMD Millipore, Billerica, MA, USA] using distilled water for $0.5 \mathrm{~h}$ at $25^{\circ} \mathrm{C}$. Furthermore, EGFR and CD133 Fab' were thiolated using 2-iminothiolane (molar ratio of Fab' to 2-iminothiolane, 1:80) (16). Thiolated EGFR and CD133 Fab' (1:1 molar ratio) were incubated with the NPs (molar ratio of Fab' to DSPE-PEG-Mal, 1:10) for $6 \mathrm{~h}$ at room temperature to facilitate antibody conjugation to 
the NPs. Subsequently, Amicon centrifugal filters (MWCO $100 \mathrm{kDa}$ ) were used to remove unconjugated Fab' for $0.5 \mathrm{~h}$ at $25^{\circ} \mathrm{C}$ by centrifugation $(2,000 \mathrm{x} \mathrm{g})$. Non-targeted NPs were developed using a similar method as aforementioned, without the addition of Fab'. Blank NPs were developed using a similar method, without the initial addition of SS. The fluorescent coumarin 6-loaded NPs were constructed using a similar method; however, coumarin 6 was initially added.

The following abbreviations were used to designate the NPs used in the present study: CD133/EGFR NPs, blank lipid-PLGA NPs conjugated with CD133 and EGFR antibodies. The SS NPs were designated as follows: SS NPs, SS lipid-PLGA NPs; CD133 SS NPs, SS lipid-PLGA NPs with CD133 antibodies; EGFR SS NPs, SS lipid-PLGA NPs with EGFR antibodies; CD133/EGFR SS NPs, SS lipid-PLGA NPs with CD133 and EGFR antibodies. The fluorescent NPs were designated as follows: Coumarin 6 NPs, coumarin 6 lipid-PLGA NPs; CD133 coumarin 6 NPs, coumarin 6 lipid-PLGA NPs with CD133 antibodies; EGFR coumarin 6 NPs, coumarin 6 lipid-PLGA NPs with EGFR antibodies; CD133/EGFR coumarin 6 NPs, coumarin 6 lipid-PLGA NPs with CD133 and EGFR antibodies.

Conjugation efficacy of antibodies to NPs. Ultrafiltration of the NPs was used to evaluate the conjugation efficacy of antibodies to NPs. Briefly, the antibodies were incubated with the NPs, and the antibody/NP mixtures were centrifuged $(2,000 \mathrm{x} \mathrm{g})$ using Amicon centrifugal filters (MWCO $100 \mathrm{kDa}$ ) to remove unconjugated antibodies for $0.5 \mathrm{~h}$ at $25^{\circ} \mathrm{C}$. The concentration of unconjugated antibodies was measured using the Pierce BCA Protein Assay Reagent kit. After measuring the antibody concentration, the conjugation efficacy of antibodies to NPs was evaluated using the following equation: $\left(M_{t}-M_{u}\right) / M_{t}$; where $M_{t}$ refers to the mass of total antibodies and MU refers to the mass of unconjugated antibodies.

Size, polydispersity index (PDI), zeta potential, morphology and drug loading of lipid-PLGA NPs. A Zetasizer Nano ZS90 (Malvern Panalytical Ltd., Malvern, UK) was used to evaluate the particle size, PDI and zeta potential of the lipid-PLGA NPs, after diluting $200 \mu \mathrm{l} \mathrm{NPs}$ in $1.8 \mathrm{ml}$ distilled water. To analyze the NP ultrastructure, the samples were stained with phosphotungstic acid, air-dried and images were captured by transmission electron microscopy (High Resolution TEM; JEM2100F; JEOL, Ltd., Tokyo, Japan). SS encapsulation efficiency (EE) and loading of the lipid-PLGA NPs was determined using reversed-phase high performance liquid chromatography (HPLC) with the universal reverse phase Diamonsil ${ }^{\circledR} \mathrm{C}-18$ column $(5 \mu \mathrm{m}, 250 \times 4.5 \mathrm{~mm}$; Dikma Technologies, Inc., Foothill Ranch, CA, USA). Briefly, $1 \mathrm{ml}$ dichloromethane was added to $2 \mathrm{mg}$ lyophilized NPs to dissolve them. Subsequently, dichloromethane was completely removed by evaporation in a vacuum, and methanol was added to dissolve the residue after thorough vortexing. Analysis (sample volume, $20 \mu \mathrm{l}$ ) was carried out using the L-2000 HPLC system (Hitachi, Ltd., Tokyo, Japan). The mobile phase was water/tetrahydrofuran/acetonitrile/phosphoric acid (v/v/v/v: $10 / 4 / 86 / 0.01$ ), and the flow rate of the mobile phase was set at $1.0 \mathrm{ml} / \mathrm{min}$. The EE of SS was calculated according to the following formula: $\mathrm{Q}_{\mathrm{E}} / \mathrm{Q}_{\mathrm{T}} \times 100 \% . \mathrm{Q}_{\mathrm{E}}$ and $\mathrm{Q}_{\mathrm{T}}$ were defined as the quantity of encapsulated SS and the total quantity of added SS, respectively. Drug loading of SS was calculated using the following formula: $\mathrm{Q}_{\mathrm{E}} / \mathrm{Q}_{\mathrm{N}} \times 100 \% . \mathrm{Q}_{\mathrm{E}}$ and $\mathrm{Q}_{\mathrm{N}}$ were defined as the quantity of encapsulated SS and the quantity of SS-loaded NPs, respectively. The detection wavelength of SS was set at $210 \mathrm{~nm}$. Furthermore, a coumarin 6 calibration curve was used to examine the drug loading of coumarin 6-loaded NPs.

SSrelease oflipid-PLGANPs. The lipid-PLGA NPs $(0.5 \mathrm{mg} / \mathrm{ml})$ were suspended in PBS or PBS containing $10 \%$ FBS in a centrifuge tube. Subsequently, the NPs were placed onto an orbital shaker and were gently agitated $(100 \mathrm{rpm})$ at $37^{\circ} \mathrm{C}$. At various time points during the 120 -h drug release period, during which the sample was continuously agitated, the centrifuge tubes were centrifuged $(10,000 \mathrm{x} \mathrm{g}$ for $30 \mathrm{~min})$ at $25^{\circ} \mathrm{C}$ to obtain the supernatant, which was further measured using reverse-HPLC, as aforementioned. The accumulated SS release rate of the NPs was measured using the following formula: $\left(M_{i} / M_{t}\right) \times 100 \%$; where $M_{i}$ refers to the mass of accumulated released $\mathrm{SS}$, and $\mathrm{M}_{\mathrm{t}}$ to the total amount of SS.

In vitro targeting of fluorescent NPs to lung cancer cells. The in vitro targeting of fluorescent NPs was evaluated as described in our previous study (10). Briefly, lung cancer cells $\left(5 \times 10^{5}\right.$ cells/well) were seeded into a 12 -well cell culture plate overnight at $37^{\circ} \mathrm{C}$. Subsequently, the medium in each well was replaced with fresh medium containing coumarin 6-loaded NPs (equal to $20 \mathrm{ng} / \mathrm{ml}$ coumarin 6). Cells were incubated with the fluorescent NPs for $2 \mathrm{~h}$ at $37^{\circ} \mathrm{C}$. After incubation, the lung cancer cells were washed with PBS to remove unbound NPs and were trypsinized to obtain dissociated single cells. Finally, the cells were directly suspended in PBS and analyzed using a FACSCalibur flow cytometer. The data were analyzed using FlowJo (version 10; FlowJo LLC).

Cytotoxic effects of NPs towards lung cancer cell lines. The cytotoxic effects of NPs were evaluated using the Cell Counting kit (CCK)-8 assay (Dojindo Molecular Technologies, Inc., Kumamoto, Japan), according to the manufacturer's protocol. Briefly, lung cancer cells were trypsinized into single cells, washed and inoculated into 96-well cell culture plates at a density of $3 \times 103$ cells/well overnight at $37^{\circ} \mathrm{C}$. Subsequently, the medium was replaced with fresh medium containing free SS or NPs at a series of concentrations. After 72-h treatment, the medium was discarded and was replaced with fresh medium. Cell viability was determined using the CCK-8 assay and a microplate reader (Multiskan MK3; Thermo Fisher Scientific, Inc.). Finally, the data were processed by GraphPad Prism 5 (GraphPad Software, Inc., La Jolla, CA, USA) to calculate the half maximal inhibitory concentration $\left(\mathrm{IC}_{50}\right)$ values.

Similarly, the cytotoxic effects of NPs were also evaluated using the MTT assay. Briefly, lung cancer cells $\left(3 \times 10^{3}\right.$ cell/well) were seeded into 96-well plates and incubated overnight at $37^{\circ} \mathrm{C}$. The medium was then replaced with fresh medium containing a series of concentrations of free SS or NPs. After 72-h treatment, the cells were washed three times with PBS to remove the formulations, and fresh medium was added to the cells. Subsequently, $20 \mu 1$ MTT solution ( $5 \mathrm{mg} / \mathrm{ml}$ in PBS) was added to each well and incubated for an additional $4 \mathrm{~h}$, 


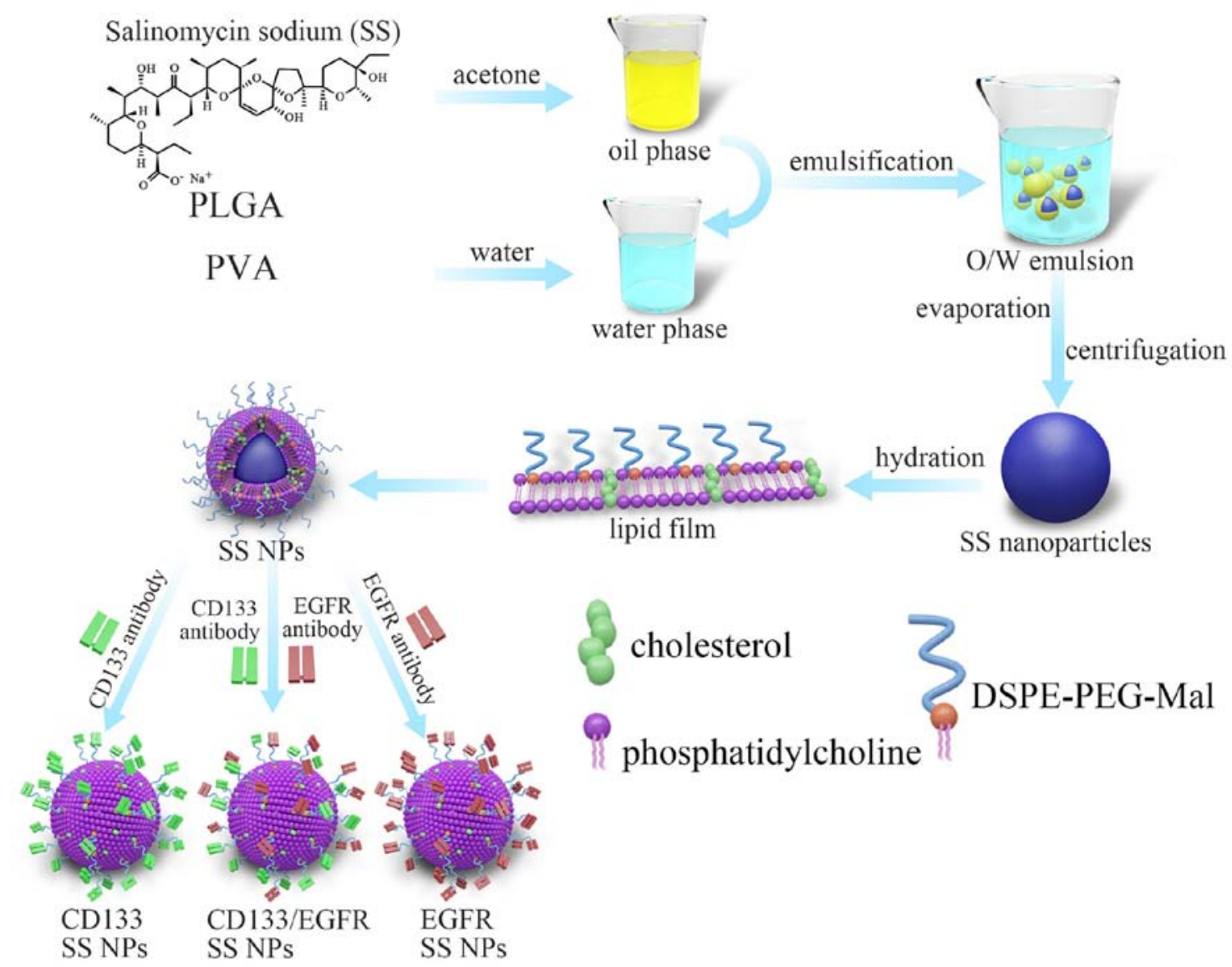

Figure 1. Generation of lipid-PLGA hybrid NPs. SS and PLGA were completely dissolved in acetone to develop the oil phase, which was slowly injected into PVA solution by homogenization. The NPs were recovered with evaporation and centrifugation, and the NPs were coated with lipid film. Thiolated EGFR and CD133 antibodies were conjugated to the NPs by the interaction of the maleimide on the NPs and the sulfhydryl groups of the antibody. CD133, cluster of differentiation 133; DSPE-PEG-Mal, 1,2-distearoyl-sn-glycero-3-phosphoethanolamine-N-[maleimide(PEG)-2000]; EGFR, epidermal growth factor receptor; NPs, nanoparticles; PLGA, poly(lactide-co-glycolide) acid; PVA, polyvinyl alcohol.

after which, the medium was replaced with $150 \mu$ l dimethyl sulfoxide per well. Absorbance was measured at $490 \mathrm{~nm}$ using a microplate reader (Multiskan MK3). Finally, the data were processed by GraphPad Prism 5 to calculate the $\mathrm{IC}_{50}$ values.

Therapeutic effects of NPs on mice bearing lung cancer xenografts. Male nude mice (age, 5 weeks; weight, $20 \mathrm{~g}$ ) were purchased from the Shanghai Chinese Academy of Sciences (Shanghai, China). The present study was approved by the Animal Administrative Committee of the Naval Medical University (Shanghai, China). The mice were housed in separate cages $(\mathrm{n}=4 \mathrm{mice} / \mathrm{cage})$ in a controlled atmosphere (humidity, $50 \pm 5 \%$; temperature, $21 \pm 1^{\circ} \mathrm{C}$ ) under a 12 -h light/dark cycle. The mice were allowed free access to food and water. A mouse model bearing a lung xenograft was established by injecting $5 \times 10^{6} \mathrm{H} 460$ cells suspended in PBS into the flank of the mice. The volume of the tumors reached $\sim 50 \mathrm{~mm}^{3}$ on day 5 . The mice were randomly divided into the following seven groups ( $\mathrm{n}=8$ mice/group): Saline, CD133/EGFR NPs, SS, SS NPs, CD133 SS NPs, EGFR SS NPs and CD133/EGFR SS NPs. On days $5,7,9,11,13,15,17,19$ and 21 , the mice were treated with NPs (suspended in PBS, $5 \mathrm{mg} \mathrm{SS} / \mathrm{kg}$, injected intravenously into the tail vein) or free SS (dissolved in ethanol, $5 \mathrm{mg} \mathrm{SS} / \mathrm{kg}$, injected intraperitoneally). Since the solubility of SS is very low in water, SS could only be dissolved in ethanol. However, intravenous injection of SS dissolved in ethanol causes toxicity to mice; therefore, free SS dissolved in ethanol could only be injected intraperitoneally. Previous studies have administered SS dissolved in ethanol intraperitoneally $(13,14)$. The tumor volume was calculated using the following formula: Volume $=$ width $^{2} \mathrm{x}$ length/2), using digital calipers, and was monitored once every 5 days. The weight of the mice was also measured once every 5 days. At the end of the antitumor assay (day 35), the mice were sacrificed using carbon dioxide. Subsequently, tumors were excised from the mice and weighed.

Tumorigenicity of lung cancer cells in vivo. The tumorigenicity of lung cancer cells in vivo was determined in 5-week old male nude mice (weight, $20 \mathrm{~g}$ ). Briefly, various densities of $\mathrm{CD}_{133^{+}}$or $\mathrm{CD} 133^{-}$lung cancer cells (between $5 \times 10^{2}$ and $1 \times 10^{6}$ cells) were isolated according to the magnetic beadbased approach. Subsequently, the collected cells were mixed with BD Matrigel ${ }^{\mathrm{TM}}$ (BD Biosciences), and implanted subcutaneously into the mice. Tumor formation was recorded during the observation period of 7 weeks.

Statistical analysis. Data were analyzed using SPSS (version 13; SPSS, Inc., Chicago, IL, USA). All of the experiments were repeated three times. Unless otherwise stated, all data are expressed as the means \pm sstandard deviation. The 
A

\begin{tabular}{cccccc}
\hline Nanoparticles & Size $(\mathrm{nm})$ & $\begin{array}{c}\text { Zeta potential } \\
\text { (mv) }\end{array}$ & PDI & Drug loading (\%) & EE (\%) \\
\hline SS NPs & $96.3 \pm 6.5$ & $-15.1 \pm 5.8$ & $0.15 \pm 0.04$ & $8.3 \pm 0.7$ & $783 \pm 6.3$ \\
CD133 SS NPs & $112.1 \pm 12.5$ & $-16.9 \pm 7.7$ & $0.16 \pm 0.06$ & $7.4 \pm 1.8$ & $77.3 \pm 8.5$ \\
EGFR SS NPs & $111.7 \pm 17.2$ & $-15.6 \pm 7.2$ & $0.12 \pm 0.03$ & $8.3 \pm 2.5$ & $76.5 \pm 6.6$ \\
CD133/EGFR SS NPs & $107.8 \pm 14.5$ & $-14.4 \pm 5.3$ & $0.18 \pm 0.05$ & $9.3 \pm 2.6$ & $78.1 \pm 7.3$ \\
\hline
\end{tabular}

B

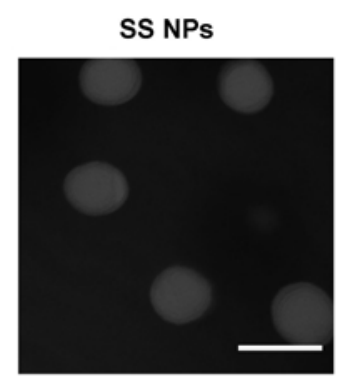

EGFR SS NPS

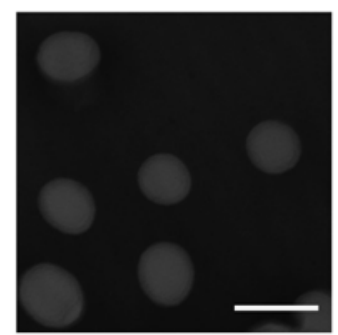

\section{CD133 SS NPs}

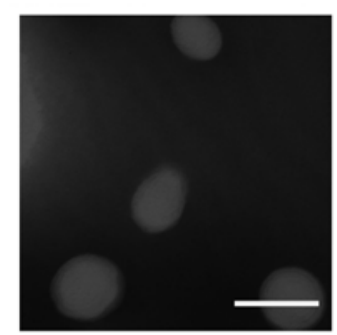

CD133/EGFR SS NPS

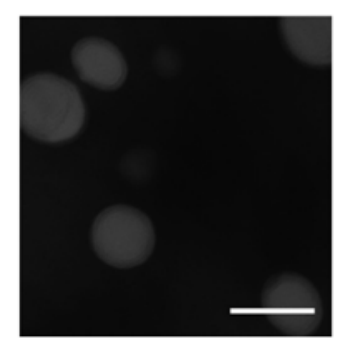

Figure 2. Characteristics of NPs. (A) Size, zeta potential, PDI, EE and drug loading of lipid-poly(lactide-co-glycolide) acid NPs. Data are presented as the means \pm standard deviation $(n=3)$. (B) Analysis by TEM. Samples were stained with phosphotungstic acid, air-dried and images were captured by TEM. Scale bars represent $100 \mathrm{~nm}$. CD133, cluster of differentiation 133; EE, encapsulation efficiency; EGFR, epidermal growth factor receptor; NPs, nanoparticles; PDI, polydispersity index; SS, salinomycin sodium. differences between two groups were measured using Student's non-paired t-test, whereas the differences among three or more groups were measured using a one-way analysis of variance with Newman-Keuls post hoc test. $\mathrm{P}<0.05$ was considered to indicate a statistically significant difference.

\section{Results}

Generation of lipid-PLGA NPs. Two steps are used to prepare lipid-PLGA NPs: The first step is to prepare the PLGA NP core by the emulsion-solvent evaporation procedure; the second step refers to coating of the PLGA NP core with the lipid shell using the lipid-film based hydration approach (Fig. 1). Subsequently, the thiolated antibodies are linked to the lipid-PLGA NPS via reaction of the sulfhydryl and maleimide groups. The size, zeta potential and drug loading of NPs are displayed in Fig. 2A. The size of SS NPs, which were not conjugated with antibodies, was small (96.3 nm). However, following conjugation of antibodies, the NP size increased to $>100 \mathrm{~nm}$; CD133 SS NPs, EGFR SS NPs and CD133/ EGFR SS NPs were 112.1, 111.7 and $107.8 \mathrm{~nm}$, respectively. The zeta potential of all NPs was $\sim 15 \mathrm{mV}$. The drug loading of all NPs ranged between 7 and 10\%, and all of the NPs exhibited an EE of $>75 \%$. To determine the conjugation efficiency of antibodies on the NPs, CD133 SS NPs, EGFR SS NPs and CD133/EGFR SS NPs were analyzed; the conjugation efficacies ranged between 15 and $18 \%$ (data not shown). TEM analysis observed that all NPs exhibited a spherical shape and a monodisperse pattern (Fig. 2B). As shown in Fig. 3, the SS release assay indicated that all NPs displayed a burst release ( $\sim 60 \%$ of SS was released in the first $24 \mathrm{~h})$. During the next $96 \mathrm{~h}$, the accumulated SS release arrived at $80 \%$, thus suggesting that all NPs displayed a sustained drug release
A

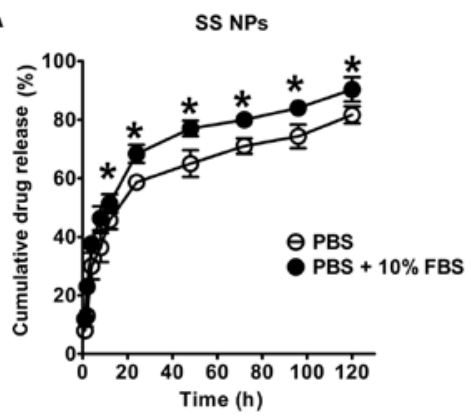

C

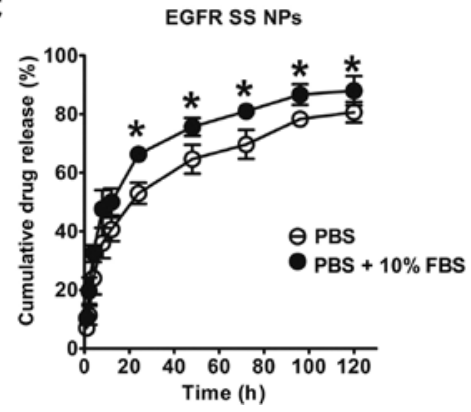

B

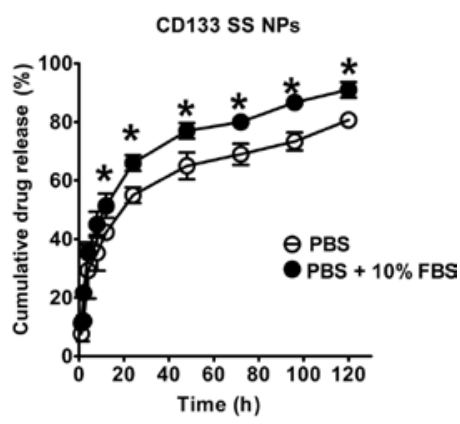

D

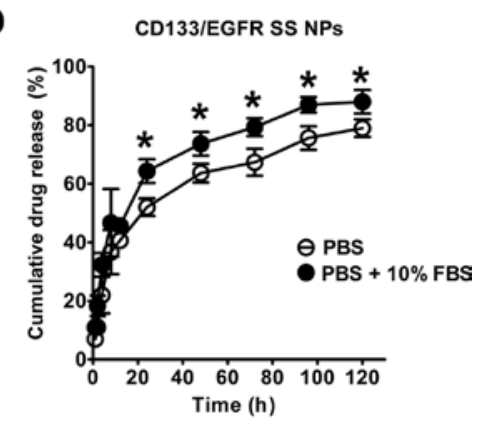

Figure 3. SS release of various NPs in PBS and PBS with 10\% FBS. (A) SS NPs, (B) CD133 SS NPs, (C) EGFR SS NPs and (D) CD133/EGFR SS NPs. The accumulated SS release rate of the NPs was measured according to the following formula: $\left(M_{i} / M_{t}\right) \times 100 \%$; where $M_{i}$ is the mass of accumulated released SS, and $\mathrm{M}_{\mathrm{t}}$ is the total amount of SS. Two groups were compared with Student's non-paired t-test. Data are presented as the means \pm sstandard deviation ( $\mathrm{n}=3$ ). ${ }^{*} \mathrm{P}<0.05$. CD133, cluster of differentiation 133; EGFR, epidermal growth factor receptor; FBS, fetal bovine serum; NPs, nanoparticles; SS, salinomycin sodium. 

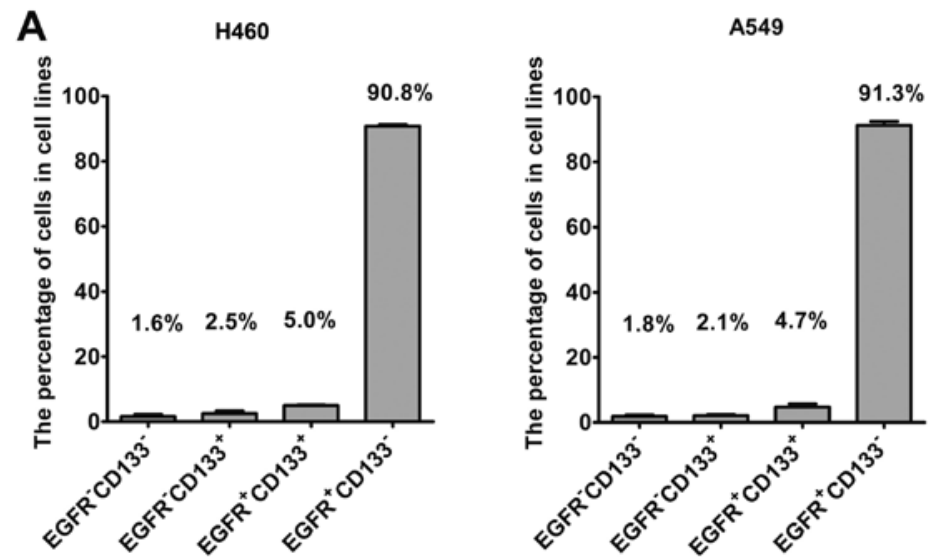

B

\begin{tabular}{cccccc}
\hline Cell types & $1 \times 10^{6}$ & $2 \times 10^{5}$ & $2 \times 10^{4}$ & $2 \times 10^{3}$ & $5 \times 10^{2}$ \\
\hline CD133- A549 cells & $4 / 8$ & $0 / 8$ & $0 / 8$ & $0 / 8$ & $0 / 8$ \\
CD133 ${ }^{+}$A549 cells & $8 / 8$ & $8 / 8$ & $8 / 8$ & $3 / 8$ & $0 / 8$ \\
CD133 $\mathrm{H} 460$ cells & $3 / 8$ & $1 / 8$ & $0 / 8$ & $0 / 8$ & $0 / 8$ \\
CD133 $^{+} \mathrm{H} 460$ cells & $8 / 8$ & $8 / 8$ & $8 / 8$ & $1 / 8$ & $0 / 8$ \\
\hline
\end{tabular}

\section{C}
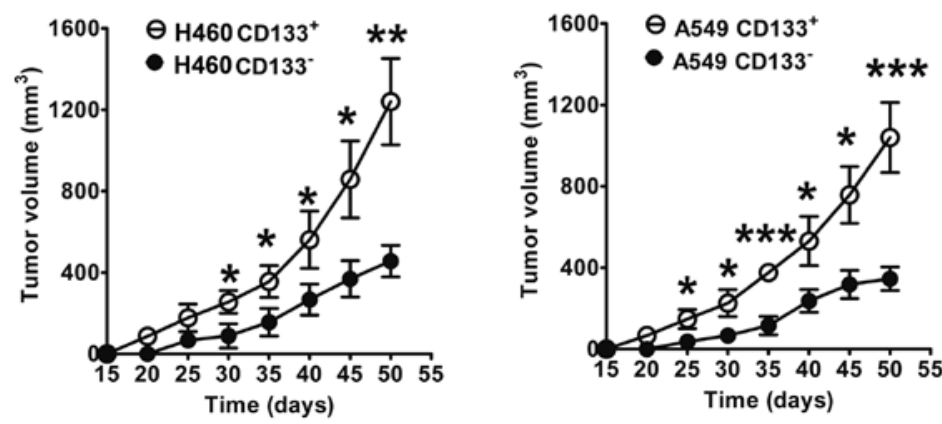

Figure 4. Characteristics of lung cancer cells. (A) Double-staining flow cytometry was conducted to analyze the expression of EGFR and CD133 in lung cancer cell lines. Data are presented as the means $\pm \mathrm{SD}(\mathrm{n}=3)$. (B) Tumorigenicity of lung cancer cells in vivo. Tumor formation was recorded during an observation period of 7 weeks. (C) Tumor growth curve induced by the $\mathrm{CD}_{133^{+}}$or $\mathrm{CD} 133^{-}$lung cancer cells $\left(1 \times 10^{6}\right)$; these cells were subcutaneously implanted into nude mice. The two groups were compared with Student's non-paired t-test. Each group consisted of 8 mice. Data are presented as the means $\pm \mathrm{SD}$. ${ }^{*} \mathrm{P}<0.05 ;{ }^{* * *} \mathrm{P}<0.01$; ${ }^{* * *} \mathrm{P}<0.001$. CD133, cluster of differentiation 133; EGFR, epidermal growth factor receptor; SD, standard deviation.

in $120 \mathrm{~h}$. Furthermore, the SS release of the NPs was markedly higher in PBS supplemented with $10 \%$ FBS $(\mathrm{P}<0.05)$ compared with in FBS-free PBS, thus suggesting that serum may facilitate the drug release of NPs.

Antigen expression and in vivo tumorigenicity of lung cancer cells. CD133 and EGFR expression was evaluated using doublestaining flow cytometry in lung cancer cells (Fig. 4A). The percentage of $\mathrm{EGFR}^{-} / \mathrm{CD} 133^{+}, \mathrm{EGFR}^{-} / \mathrm{CD} 133^{-}, \mathrm{EGFR}^{+} / \mathrm{CD} 133^{+}$ and $\mathrm{EGFR}^{+} / \mathrm{CD}_{133}$ - in $\mathrm{H} 460$ cells was 2.5 , 1.6, 5.0 and $90.8 \%$,

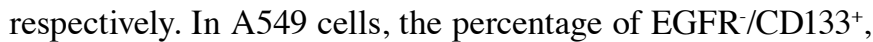
$\mathrm{EGFR}^{-} / \mathrm{CD} 133^{-}, \mathrm{EGFR}^{+} / \mathrm{CD} 133^{+}$and $\mathrm{EGFR}^{+} / \mathrm{CD}^{-} 3^{-}$was 2.1, $1.8,4.7$ and $91.3 \%$, respectively. These results indicated that the expression levels of EGFR and CD133 in lung cancer cells are heterogeneous, as reflected by the different subpopulations in the lung cancer cell lines. Prior to magnetic sorting-based isolation, the percentage of $\mathrm{CD}_{133}{ }^{+}$cells was 7.5 and $6.8 \%$ in
H460 and A549 cells, respectively, whereas the percentage of $\mathrm{CD} 133^{+}$cells in isolated $\mathrm{CD} 133^{+}$cells was $>98 \%$ following magnetic sorting-based isolation. Conversely, in sorted CD133 cells, the percentage of $\mathrm{CD}_{133}{ }^{+}$cells was $<2 \%$.

The present study also evaluated the tumorigenicity of $\mathrm{CD}_{133^{+}}$and $\mathrm{CD} 133^{-}$lung cancer cells in mice (Fig. 4B and C). Notably, $100 \%$ tumor incidence $(8 / 8)$ was detected in mice treated with $\geq 2 \times 10^{4} \mathrm{CD} 33^{+}$A549 cells (Fig. 4B). Conversely, only $50 \%$ tumor incidence $(4 / 8)$ was detected in mice treated with CD133- A549 cells, even when they were treated with the maximum cell number $\left(1 \times 10^{6}\right)$, thus indicating that $\mathrm{CD} 133^{+}$A549 cells significantly increased tumorigenic potential compared with CD133- A549 cells. Similarly, $\mathrm{CD}_{133}{ }^{+} \mathrm{H} 460$ cells had significantly increased tumorigenic potential compared with $\mathrm{CD} 133^{-} \mathrm{H} 460$ cells. $\mathrm{CD}^{-3} 3^{+} \mathrm{H} 460$ cells resulted in $100 \%$ tumor incidence in mice when the cell count was $\geq 2 \times 10^{4}$ cells, whereas $1 \times 10^{6}$ CD133- H460 cells 
A

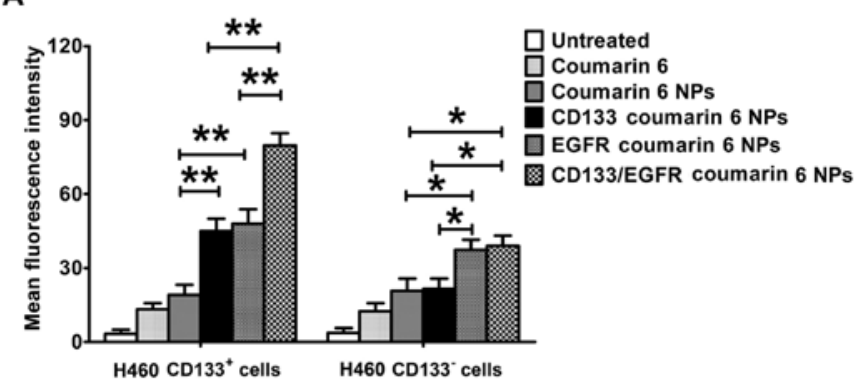

B

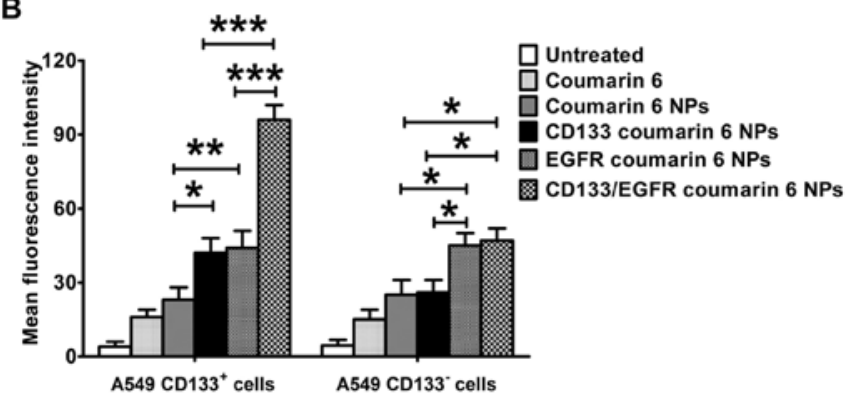

Figure 5. In vitro uptake of fluorescent NPs in lung cancer cells. (A) H460 and (B) A549 cells. The difference between groups was evaluated by one-way analysis of variance with the Newman-Keuls post hoc test. Data are presented as the means \pm sstandard deviation $(\mathrm{n}=3) .{ }^{*} \mathrm{P}<0.05 ;{ }^{* *} \mathrm{P}<0.01$ ${ }^{* * *} \mathrm{P}<0.001$. CD133, cluster of differentiation 133; EGFR, epidermal growth factor receptor; NPs, nanoparticles.

only produced $37.5 \%$ tumor incidence (3/8). Furthermore, the growth curves of tumors in mice formed by $1 \times 10^{6}$ lung cancer cells were evaluated (Fig. 4C). After 30 days, the volume of tumors induced by $\mathrm{CD} 133^{+} \mathrm{H} 460$ cells was significantly larger compared with $\mathrm{CD}^{-} 3^{-} \mathrm{H} 460$ cells $(\mathrm{P}<0.05)$. On day 50, the volume of the tumors induced by $\mathrm{CD} 133^{+} \mathrm{H} 460$ cells was $\sim 1,200 \mathrm{~mm}^{3}$, which was markedly larger than the volume of tumors induced by CD133- $\mathrm{H} 460$ cells $\left(\sim 400 \mathrm{~mm}^{3}\right.$; $\mathrm{P}<0.01$; Fig. 4C). In A549 cells, similar results were obtained. These findings indicated that the tumorigenicity of $\mathrm{CD}_{133^{+}}$lung cancer cells was markedly higher than CD133- lung cancer cells, thus suggesting that $\mathrm{CD} 133^{+}$lung cancer cells possessed the characteristics of lung CICs.

Targeting of fluorescent NPs to lung cancer cells in vitro. As a common green fluorescent tracer, coumarin 6 was used to evaluate the in vitro targeting of fluorescent NPs to lung cancer cells (Fig. 5). In CD133+ H460 cells, the uptake of CD133/ EGFR coumarin 6 NPs was significantly higher compared with EGFR coumarin 6 NPs and CD133 coumarin 6 NPs $(\mathrm{P}<0.01$; Fig. 5A). Both EGFR coumarin 6 NPs and CD133 coumarin 6 NPs exhibited increased uptake compared with coumarin 6 NPs $(\mathrm{P}<0.01)$. However, CD133/EGFR coumarin 6 NPs exhibited similar uptake to EGFR coumarin 6 NPs in CD133- 4460 cells, but exhibited increased uptake compared with CD133 coumarin 6 NPs and coumarin 6 NPs $(\mathrm{P}<0.05)$. In A549 cells, similar results were achieved (Fig. 5B). CD133/EGFR coumarin 6 NPs exhibited increased uptake compared with EGFR coumarin 6 NPs and CD133 coumarin 6 NPs in $\mathrm{CD}_{133}{ }^{+}$A549 cells $(\mathrm{P}<0.001)$. In addition, CD133/EGFR coumarin 6 NPs exhibited increased uptake compared with CD133 coumarin 6 NPs and coumarin 6 NPs in CD133- A549 cells $(\mathrm{P}<0.05)$. EGFR coumarin 6 NPs also showed increased uptake compared with CD133 coumarin 6 NPs and coumarin 6 NPs in CD133- A549 cells $(\mathrm{P}<0.05)$.

Cytotoxic effects of SS and lipid-PLGA NPs on lung cancer cells. As shown in Fig. 6, CD133/EGFR NPs, blank lipid-
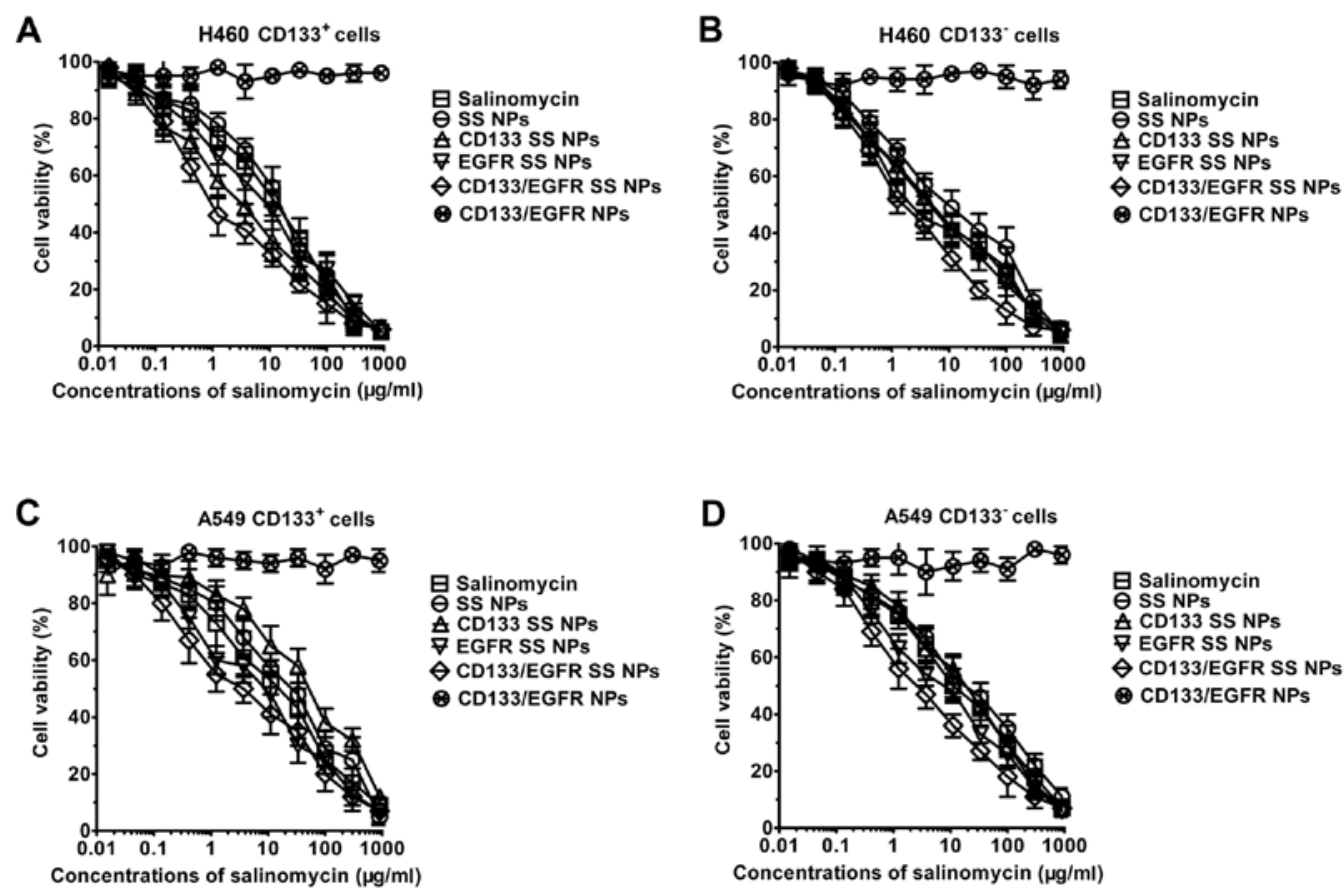

Figure 6. Cytotoxicity of NPs on lung cancer cells, as determined using the Cell Counting kit-8 assay. (A) H460 CD133+ cells, (B) H460 CD133- cells, (C) A549 CD133 ${ }^{+}$cells and (D) A549 CD133 cells. Data are presented as the means \pm sstandard deviation (n=3). CD133, cluster of differentiation 133; EGFR, epidermal growth factor receptor; NPs, nanoparticles; SS, salinomycin sodium. 
Table I. Cytotoxicity of SS and NPs, as reflected by $\mathrm{IC}_{50}$, on lung cancer cells.

\begin{tabular}{|c|c|c|c|c|}
\hline \multirow[b]{3}{*}{ Treatment } & \multicolumn{4}{|c|}{$\mathrm{IC}_{50}$ value $(\mu \mathrm{g} / \mathrm{ml})$} \\
\hline & \multicolumn{2}{|c|}{$\mathrm{H} 460$} & \multicolumn{2}{|c|}{ A549 } \\
\hline & $\mathrm{CD}_{133^{+}}$ & CD133- & $\mathrm{CD}_{133^{+}}$ & CD133- \\
\hline SS & $6.3 \pm 2.5$ & $13.6 \pm 3.5$ & $6.6 \pm 2.4$ & $17.5 \pm 5.8$ \\
\hline SS NPs & $7.8 \pm 1.6$ & $15.1 \pm 3.8$ & $8.7 \pm 2.9$ & $21.2 \pm 4.8$ \\
\hline CD133 SS NPs & $3.2 \pm 1.1^{\mathrm{a}}$ & $17.3 \pm 4.9$ & $5.3 \pm 2.7^{\mathrm{a}}$ & $25.9 \pm 6.9$ \\
\hline EGFR SS NPs & $3.8 \pm 1.3^{\mathrm{a}}$ & $7.3 \pm 2.8^{\mathrm{a}}$ & $5.2 \pm 2.3^{\mathrm{a}}$ & $7.8 \pm 1.8^{\mathrm{a}}$ \\
\hline CD133/EGFR SS NPs & $1.1 \pm 0.4^{\mathrm{a}-\mathrm{c}}$ & $6.7 \pm 2.7^{\mathrm{a}, \mathrm{b}}$ & $1.4 \pm 0.7^{\mathrm{a}-\mathrm{c}}$ & $4.3 \pm 1.5^{\mathrm{a}, \mathrm{b}}$ \\
\hline CD133/EGFR NPs & $>270.0$ & $>270.0$ & $>270.0$ & $>270.0$ \\
\hline
\end{tabular}

Data are expressed as the means \pm sstandard deviation $(n=3)$. CD133, cluster of differentiation 133; EGFR, epidermal growth factor receptor; $\mathrm{IC}_{50}$, half maximal inhibitory concentration; NPs, nanoparticles; SS, salinomycin sodium. ${ }^{\mathrm{a} P}<0.05$ vs. SS NPs; ${ }^{\text {P }}<0.05$ vs. CD133 SS NPs; ${ }^{\mathrm{c}} \mathrm{P}<0.05$ vs. EGFR SS NPs.

Table II. Cytotoxicity of SS and NPs, as reflected by $\mathrm{IC}_{50}$, on lung cancer cells measured by the MTT assay.

\begin{tabular}{|c|c|c|c|c|}
\hline \multirow[b]{3}{*}{ Treatment } & \multicolumn{4}{|c|}{$\mathrm{IC}_{50}$ value $(\mu \mathrm{g} / \mathrm{ml})$} \\
\hline & \multicolumn{2}{|c|}{ H460 } & \multicolumn{2}{|c|}{ A549 } \\
\hline & $\mathrm{CD}_{133^{+}}$ & CD133- & $\mathrm{CD}_{133}{ }^{+}$ & CD133- \\
\hline SS & $8.9 \pm 2.8$ & $17.8 \pm 2.9$ & $9.3 \pm 3.3$ & $19.2 \pm 6.3$ \\
\hline SS NPs & $9.3 \pm 2.1$ & $18.3 \pm 4.9$ & $9.5 \pm 1.5$ & $23.5 \pm 7.2$ \\
\hline CD133 SS NPs & $4.1 \pm 1.5$ & $20.5 \pm 6.3$ & $7.1 \pm 3.7$ & $28.2 \pm 7.3$ \\
\hline EGFR SS NPs & $4.2 \pm 1.1$ & $9.8 \pm 3.1$ & $8.1 \pm 1.5$ & $6.6 \pm 2.4$ \\
\hline CD133/EGFR SS NPs & $1.5 \pm 0.3$ & $7.8 \pm 3.6$ & $3.2 \pm 1.3$ & $5.8 \pm 2.6$ \\
\hline CD133/EGFR NPs & $>270.0$ & $>270.0$ & $>270.0$ & $>270.0$ \\
\hline
\end{tabular}

Data are expressed as the means \pm sstandard deviation $(n=3)$. CD133, cluster of differentiation 133; EGFR, epidermal growth factor receptor; $\mathrm{IC}_{50}$, half maximal inhibitory concentration; NPs, nanoparticles; SS, salinomycin sodium.

PLGA NPs with CD133 and EGFR antibodies, displayed no marked cytotoxic effects towards lung cancer cells, and the curve induced by CD133/EGFR NPs was almost horizontal. Conversely, dose-dependent cytotoxicity was observed for SS and SS NPs, as indicated by the inverse sigmoid curves. The $\mathrm{IC}_{50}$ values of the drugs are presented in Table I. In CD133+ H460 cells, SS NPs exhibited similar cytotoxic effects to SS ( 7.8 vs. $6.3 \mu \mathrm{g} / \mathrm{ml}$ ). Compared with SS NPs, CD133 SS NPs and EGFR SS NPs possessed significantly increased cytotoxic effects $(3.2 \mu \mathrm{g} / \mathrm{ml}$ for CD133 SS NPs, $3.8 \mu \mathrm{g} / \mathrm{ml}$ for EGFR SS NPs; P<0.05). Notably, the cytotoxic effects of CD133/EGFR SS NPs were significantly higher than the other groups, including EGFR SS NPs, CD133 SS NPs and SS NPs $(\mathrm{P}<0.05)$. Nevertheless, the $\mathrm{IC}_{50}$ values of $\mathrm{CD} 133$ SS NPs $(17.3 \mu \mathrm{g} / \mathrm{ml})$ and SS NPs $(15.1 \mu \mathrm{g} / \mathrm{ml})$ did not differ significantly in CD133- H460 cells. In CD133- H460 cells, compared with SS NPs $(15.1 \mu \mathrm{g} / \mathrm{ml})$ and CD133 SS NPs $(17.3 \mu \mathrm{g} / \mathrm{ml})$, the $\mathrm{IC}_{50}$ values of CD133/EGFR SS NPs $(6.7 \mu \mathrm{g} /$ $\mathrm{ml})$ and EGFR SS NPs $(7.3 \mu \mathrm{g} / \mathrm{ml})$ were significantly lower $(\mathrm{P}<0.05)$. In A549 cells, similar results were achieved.
In $\mathrm{CD}_{133^{+}} \mathrm{A} 549$ cells, the cytotoxic effects of CD133/ EGFR SS NPs were markedly higher compared with the other groups, including SS NPs, CD133 SS NPs and EGFR SS NPs $(\mathrm{P}<0.05)$. In addition, the cytotoxic effects of CD133/ EGFR SS NPs were significantly higher than the other groups, including SS NPs and CD133 SS NPs in CD133- A549 cells $(\mathrm{P}<0.05)$. Consistent with the CCK-8 assay, similar results were obtained using the MTT assay. As shown in Table II, in $\mathrm{CD}_{133^{+}} \mathrm{H} 460$ and A549 cells, the cytotoxic effects of CD133/ EGFR SS NPs were significantly higher than the other groups, including EGFR SS NPs, CD133 SS NPs and SS NPs $(\mathrm{P}<0.05)$. In CD133 ${ }^{-} 460$ cells and A549 cells, the cytotoxic effects of CD133/EGFR SS NPs were significantly higher than the other groups, including SS NPs and CD133 SS NPs $(\mathrm{P}<0.05)$.

Taken together, CD133/EGFR SS NPs exhibited enhanced cytotoxic effects compared with CD133 SS NPs, EGFR SS NPs, SS NPs and SS in CD133+ lung cancer cells. Furthermore, CD133/EGFR SS NPs exhibited enhanced cytotoxic effects compared with CD133 SS NPs, SS NPs and SS in CD133- lung cancer cells. 


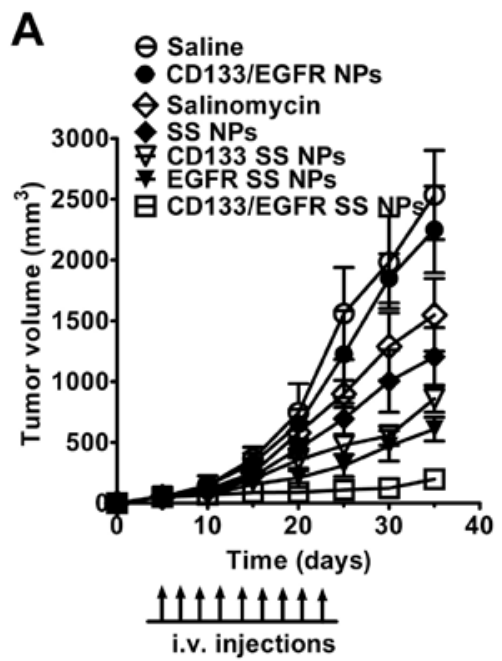

B
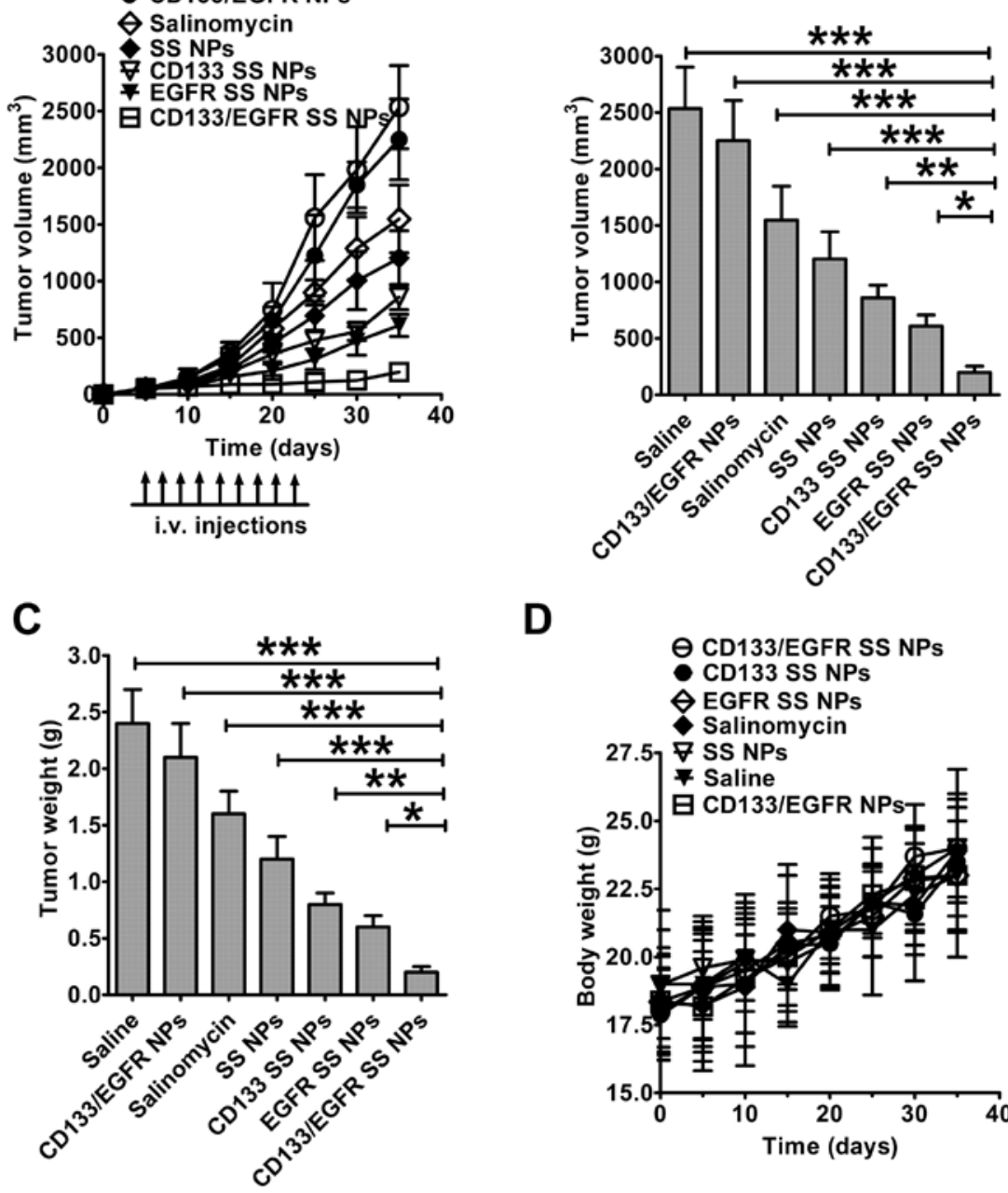

D

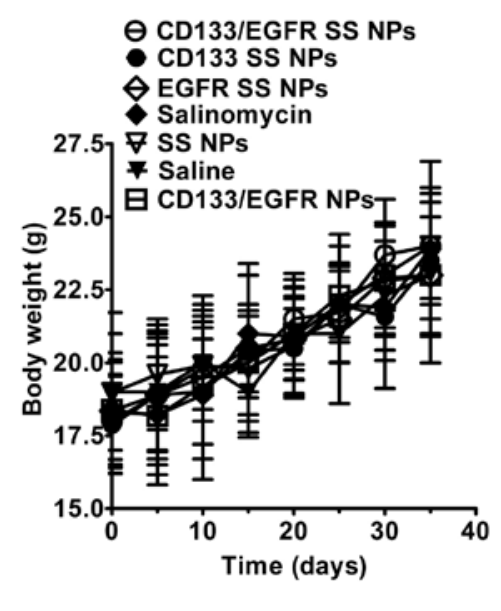

Figure 7. Therapeutic effects of lipid-poly(lactide-co-glycolide) acid NPs on lung cancer-bearing mice. (A) Tumor growth in mice bearing lung xenografts following treatment with NPs. Each group consisted of 8 mice. Data are presented as the means \pm SD. (B) At the endpoint, the volume of excised tumors was calculated. (C) Weight of excised tumors. (D) Weight of the mice was monitored during the whole treatment duration. Data are presented as the means \pm SD $(\mathrm{n}=8)$. The difference between groups was evaluated by one-way analysis of variance with the Newman-Keuls post hoc test. ${ }^{*} \mathrm{P}<0.05 ;{ }^{* * *} \mathrm{P}<0.01 ;{ }^{* * *} \mathrm{P}<0.001$. CD133, cluster of differentiation 133; EGFR, epidermal growth factor receptor; NPs, nanoparticles; SS, salinomycin sodium.

Therapeutic effects of lipid-PLGA NPS on lung cancerbearing mice. The therapeutic effects of lipid-PLGA NPs were examined in lung cancer-bearing mice (Fig. 7). The tumors of mice treated with CD133/EGFR NPs progressed as rapidly as in saline-treated mice, due to the absence of SS in CD133/EGFR NPs (Fig. 7A). SS and SS NPs achieved mild therapeutic efficacy (39 and 52\% decrease in tumor volume compared with saline, respectively). Notably, CD133/ EGFR SS NPs obtained a 92\% decrease in tumor volume, whereas EGFR SS NPs and CD133 SS NPs only obtained moderate (75 and 66\% decrease in tumor volume) therapeutic efficacy, respectively. Notably, tumor volume in the CD133/ EGFR SS NPs-treated group was the smallest among all of the groups (CD133/EGFR SS NPs vs. SS NPs and SS, P<0.001; CD133/EGFR SS NPs vs. CD133 SS NPs, $\mathrm{P}<0.01$; CD133/ EGFR SS NPs vs. EGFR SS NPs, P<0.05; Fig. 7B). The CD133/ EGFR SS NPs-treated group exhibited the smallest tumor weight compared with the other groups (CD133/EGFR SS NPs vs. SS NPs and SS: P<0.001; CD133/EGFR SS NPs vs. CD133 SS NPs, P<0.01; CD133/EGFR SS NPs vs.
EGFR SS NPs, P<0.05; Fig. 7C). All of the mice showed a steady weight increase during the treatment, and did not exhibit significant weight loss (Fig. 7D).

\section{Discussion}

Recent evidence has indicated that CICs should be targeted together with cancer cells to achieve a better therapeutic effect $(11,14)$. Since EGFR and CD133 are markers of lung cancer cells and CICs, respectively, the present study constructed dual-targeting lipid-PLGA hybrid NPs, named CD133/EGFR SS NPs, to target lung CICs and cancer cells. In the present study, CD133/EGFR SS NPs exhibited significantly improved therapeutic effects in lung cancer compared with free SS, and non-targeted or single-targeting NPs.

Poor safety hampers the potential use of inorganic NPs in the clinic $(25,27)$. Conversely, due to their superior safety, biodegradable organic NPs are considered to be more promising in clinical applications $(25,27)$. CD133/EGFR SS NPs are composed of PLGA, phosphatidylcholine and cholesterol; 


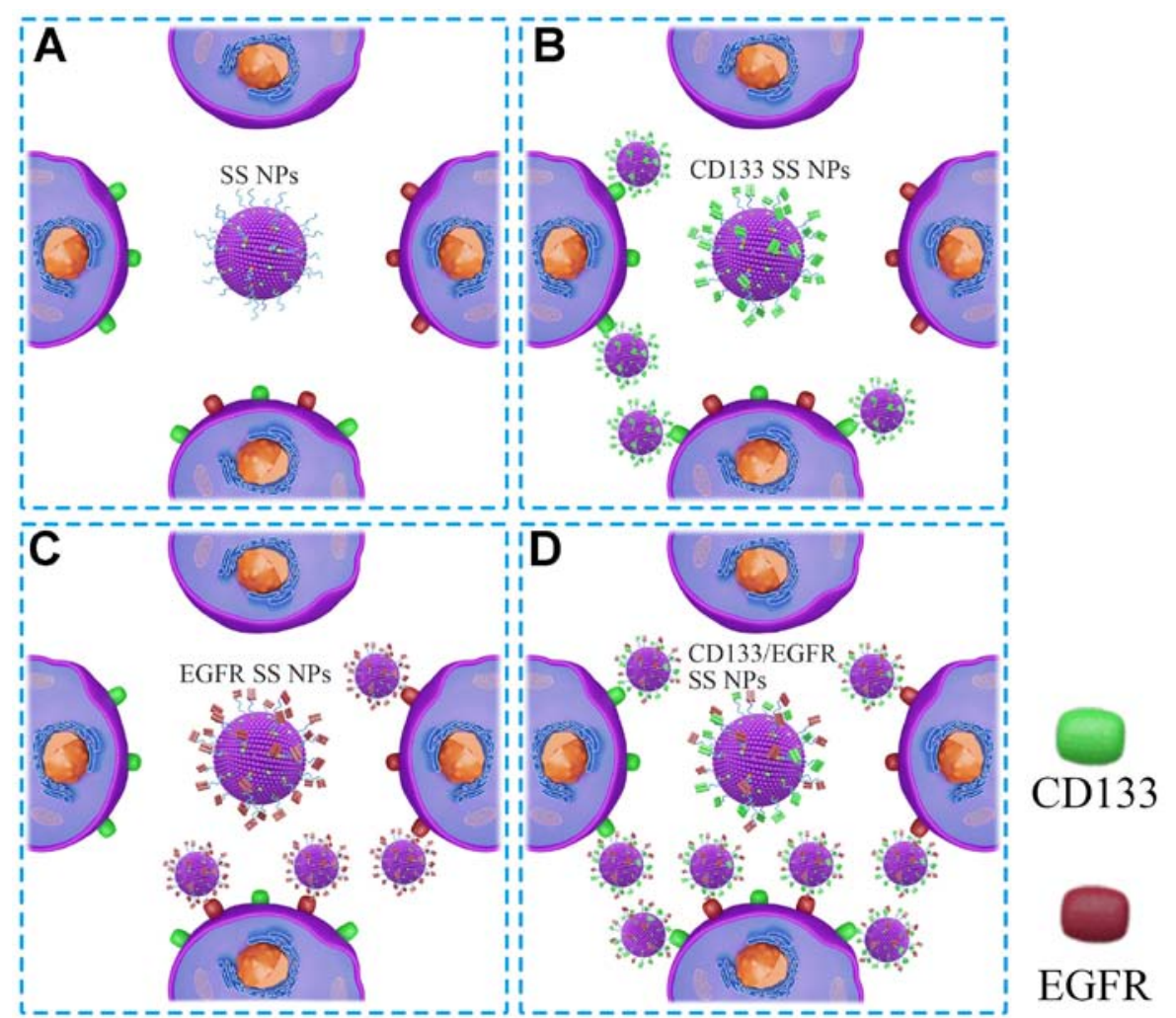

Figure 8. Diagram of the mechanism underlying the superior therapeutic efficacy of CD133/EGFR SS NPs towards lung cancer. (A) SS NPs could not target any lung cancer cells, due to the absence of antibody conjugation; (B) CD133 SS NPs could only target EGFR ${ }^{+}$CD133 ${ }^{+}$cells and EGFR CD133 ${ }^{+}$cells, but not EGFR ${ }^{+}$CD133- and EGFR CD133- cells; (C) EGFR SS NPs could only target EGFR ${ }^{+}{ }^{-}{ }^{-}{ }^{-} 133^{+}$cells and EGFR ${ }^{+}$CD133- cells, but not EGFR'CD133 cells and EGFR CD133 ${ }^{+}$cells; (D) CD133/EGFR SS NPs could target EGFR ${ }^{+}$CD133- EGFR $^{+} \mathrm{CD}^{-} 133^{+}$cells and EGFR-CD133 ${ }^{+}$cells. CD133, cluster of differentiation 133; EGFR, epidermal growth factor receptor; NPs, nanoparticles; SS, salinomycin sodium.

all of these materials have been approved by the Food and Drug Administration. In a pilot clinical trial containing patients with cancer, the therapeutic effects of the polyether antibiotic SS have been examined; the results indicated that SS may be administered to patients with no severe side effects (13). In the present study, blank lipid-PLGA NPs with EGFR and CD133 antibodies had good biocompatibility as determined by the CCK-8 assay. Furthermore, no significant weight loss was detected in mice following treatment with the prepared SS NPs. Therefore, the NPs generated in the present study have been demonstrated to possess good safety profiles.

The selection of antibodies contributes significantly to the specific targeting of developed NPs to lung cancer cells. Since non-CICs can be transformed to CICs, it is essential to increase the cytotoxicity of NPs towards CD133- lung cancer cells. The present study developed CD133/EGFR SS NPs, which are dual-targeting lipid-PLGA hybrid NPs, to target and eliminate $\mathrm{CD}^{-133^{+}}$and CD133- lung cancer cells. The results demonstrated that, in CD133+ lung cancer cells, CD133/EGFR SS NPs exhibited significantly increased cytotoxic effects compared with CD133 SS NPs, EGFR SS NPs and SS NPs. In CD133- lung cancer cells, CD133/EGFR SS NPs also exhibited increased cytotoxic effects compared with CD133 SS NPs and SS NPs. These data suggested that CD133/EGFR SS NPs may increase targeting and therapeutic effects towards both lung CICs and lung cancer cells.

The targeting of CD133/EGFR SS NPs to CD133, which is a marker of stem cells, may have potential risk to normal hematopoietic stem cells. In our further studies, the following strategy may be adopted to reduce the potential risk to normal hematopoietic stem cells; intratumoral administration of CD133/EGFR SS NPs may increase the accumulation of NPs in tumors, thus resulting in reduced distribution of NPs in bone marrow.

The present results helped to clarify the anticancer mechanism underlying CD133/EGFR SS NPs (Fig. 8). As demonstrated by flow cytometry, lung cancer cells did not exhibit homogeneous antigen expression, and were composed of four cell populations $\left(\mathrm{EGFR}^{+} / \mathrm{CD}^{-} 33^{+}, \mathrm{EGFR} / \mathrm{CD} 133^{-}\right.$, $\mathrm{EGFR}^{+} / \mathrm{CD} 133^{-}$and $\left.\mathrm{EGFR}^{-} / \mathrm{CD} 133^{+}\right)$. Due to the absence of EGFR or CD133 antibodies, SS NPs did not target the four cell populations. CD133 SS NPs exhibited enhanced targeting to $\mathrm{EGFR}^{+} / \mathrm{CD}_{133^{+}}$and $\mathrm{EGFR} / \mathrm{CD} 133^{+}$cells, whereas EGFR SS NPs exhibited enhanced targeting to $\mathrm{EGFR}^{+} /$ $\mathrm{CD}_{133^{+}}$and $\mathrm{EGFR}^{+} / \mathrm{CD}_{133}{ }^{-}$cells. Notably, the targeting of CD133/EGFR SS NPs to $\mathrm{EGFR}^{+} / \mathrm{CD} 133^{+}, \mathrm{EGFR}^{+} / \mathrm{CD} 133^{-}$and $\mathrm{EGFR}^{-} / \mathrm{CD} 133^{+}$cells was enhanced due to the conjugation of double antibodies. Furthermore, CD133/EGFR SS NPs exhibited enhanced targeting to $\mathrm{EGFR}^{+} / \mathrm{CD} 133^{+}$cells compared with CD133 SS NPs and EGFR SS NPs, since the antigen density on target cells is closely associated with the targeting of antibody-conjugated NPs, and the antigen density can be artificially increased according to the targeting of two antigens (EGFR and CD133) on target cells (27). Taken together, these findings may explain why CD133/EGFR SS NPs exerted significantly increased therapeutic efficacy towards CD133+ 
lung CICs compared with CD133 SS NPs, EGFR SS NPs and SS NPs, and markedly enhanced therapeutic efficacy to CD133- lung cancer cells compared with CD133 SS NPs and SS NPs.

The effects of NP treatment on the immune response against tumor growth may require evaluation, in order to prove the efficacy of NPs. The main observations used to determine the anticancer effects in the present study focused on tumor weight and volume; the immune response was not analyzed in this study. The in vivo anticancer effects of SS-loaded NPs or liposomes have been investigated in previous studies $(10,11)$, whereas the effects of SS-based treatment on the immune response against tumor growth have not been investigated. Therefore, the present study did not test the effects of SS-based treatment on the immune response against tumor growth. However, the importance of testing the immune effects of this treatment have been recognized, and will potentially be analyzed in future studies.

In conclusion, recent evidence has indicated that CICs, together with cancer cells, should be targeted to achieve superior therapeutic effects against cancer. The present study developed CD133/EGFR SS NPs, which efficiently increased SS delivery to lung CICs and lung cancer cells, and may therefore represent an effective treatment for lung cancer.

\section{Acknowledgements}

Not applicable.

\section{Funding}

This study was supported by the Project of Minhang District Science and Technology Committee (grant no. 2015MHZ064) and the 2016 Fund of the Central Hospital of Minhang District (grant no. 2016MHLC08).

\section{Availability of data and materials}

All data generated or analyzed during this study are included in this published article.

\section{Authors' contributions}

QP contributed to the design of the study and wrote the manuscript. JZ and HC performed the experiments. JS analyzed the data. All authors have read and approved this manuscript.

\section{Ethics approval and consent to participate}

The experimental protocols were approved by the Animal Administrative Committee of the Naval Medical University (Shanghai, China).

\section{Patient consent for publication}

Not applicable.

\section{Competing interests}

The authors declare that they have no competing interests.

\section{References}

1. Siegel RL, Miller KD and Jemal A: Cancer Statistics, 2017. CA Cancer J Clin 67: 7-30, 2017.

2. Chen W, Zheng R, Baade PD, Zhang S, Zeng H, Bray F, Jemal A, $\mathrm{Yu}$ XQ and He J: Cancer statistics in China, 2015. CA Cancer J Clin 66: 115-132, 2016.

3. Eramo A, Lotti F, Sette G, Pilozzi E, Biffoni M, Di Virgilio A, Conticello C, Ruco L, Peschle C and De Maria R: Identification and expansion of the tumorigenic lung cancer stem cell population. Cell Death Differ 15: 504-514, 2008.

4. Kim JJ and Tannock IF: Repopulation of cancer cells during therapy: An important cause of treatment failure. Nat Rev Cancer 5: 516-525, 2005.

5. Zakaria N, Satar NA, Abu Halim NH, Ngalim SH, Yusoff NM, Lin J and Yahaya BH: Targeting lung cancer stem cells: Research and clinical impacts. Front Oncol 7: 80, 2017.

6. Bertolini G, Roz L, Perego P, Tortoreto M, Fontanella E, Gatti L, Pratesi G, Fabbri A, Andriani F, Tinelli S, et al: Highly tumorigenic lung cancer $\mathrm{CD} 133^{+}$cells display stem-like features and are spared by cisplatin treatment. Proc Natl Acad Sci USA 106: 16281-16286, 2009.

7. Chaffer CL, Brueckmann I, Scheel C, Kaestli AJ, Wiggins PA, Rodrigues LO, Brooks M, Reinhardt F, Su Y, Polyak K, et al: Normal and neoplastic nonstem cells can spontaneously convert to a stem-like state. Proc Natl Acad Sci USA 108: 7950-7955, 2011.

8. Gupta PB, Fillmore CM, Jiang G, Shapira SD, Tao K, Kuperwasser $\mathrm{C}$ and Lander ES: Stochastic state transitions give rise to phenotypic equilibrium in populations of cancer cells. Cell 146: 633-644, 2011.

9. Iliopoulos D, Hirsch HA, Wang G and Struhl K: Inducible formation of breast cancer stem cells and their dynamic equilibrium with non-stem cancer cells via IL6 secretion. Proc Natl Acad Sci USA 108: 1397-1402, 2011.

10. Gong Z, Chen D, Xie F, Liu J, Zhang H, Zou H, Yu Y, Chen Y, Sun Z, Wang X, et al: Codelivery of salinomycin and doxorubicin using nanoliposomes for targeting both liver cancer cells and cancer stem cells. Nanomedicine (Lond) 11: 2565-2579, 2016.

11. Xie F, Zhang S, Liu J, Gong Z, Yang K, Zhang H, Lu Y, Zou H, $\mathrm{Yu}$ Y, Chen Y, et al: Codelivery of salinomycin and chloroquine by liposomes enables synergistic antitumor activity in vitro. Nanomedicine (Lond) 11: 1831-1846, 2016.

12. Wang Y: Effects of salinomycin on cancer stem cell in human lung adenocarcinoma A549 cells. Med Chem 7: 106-111, 2011.

13. Naujokat $C$ and Steinhart R: Salinomycin as a drug for targeting human cancer initiating cells. J Biomed Biotechnol 2012: 950658, 2012.

14. Zhang Y, Zhang Q, Sun J, Liu H and Li Q: The combination therapy of salinomycin and gefitinib using poly(d,1-lactic-coglycolic acid)-poly(ethylene glycol) nanoparticles for targeting both lung cancer stem cells and cancer cells. OncoTargets Ther 10: 5653-5666, 2017

15. Ketola K, Hilvo M, Hyötyläinen T, Vuoristo A, Ruskeepää AL, Orešič M, Kallioniemi O and Iljin K: Salinomycin inhibits prostate cancer growth and migration via induction of oxidative stress. Br J Cancer 106: 99-106, 2012.

16. Gao J, Xia Y, Chen H, Yu Y, Song J, Li W, Qian W, Wang H, Dai J and Guo Y: Polymer-lipid hybrid nanoparticles conjugated with anti-EGF receptor antibody for targeted drug delivery to hepatocellular carcinoma. Nanomedicine (Lond) 9: 279-293, 2014.

17. Kapoor DN, Bhatia A, Kaur R, Sharma R, Kaur G and Dhawan S: PLGA: A unique polymer for drug delivery. Ther Deliv 6: 41-58, 2015.

18. Gao J, Chen H, Song H, Su X, Niu F, Li W, Li B, Dai J, Wang H and Guo Y: Antibody-targeted immunoliposomes for cancer treatment. Mini Rev Med Chem 13: 2026-2035, 2013.

19. Gao J, Feng SS and Guo Y: Antibody engineering promotes nanomedicine for cancer treatment. Nanomedicine (Lond) 5: 1141-1145, 2010.

20. Wang J, Wu Z, Pan G, Ni J, Xie F, Jiang B, Wei L, Gao J and Zhou W: Enhanced doxorubicin delivery to hepatocellular carcinoma cells via CD147 antibody-conjugated immunoliposomes. Nanomedicine: Oct 16, 2017 (Epub ahead of print). pii: S1549-9634(17)30179-X.

21. Paez JG, Jänne PA, Lee JC, Tracy S, Greulich H, Gabriel S, Herman P, Kaye FJ, Lindeman N, Boggon TJ, et al: EGFR mutations in lung cancer: Correlation with clinical response to gefitinib therapy. Science 304: 1497-1500, 2004. 
22. Sos ML, Koker M, Weir BA, Heynck S, Rabinovsky R, Zander T, Seeger JM, Weiss J, Fischer F, Frommolt P, et al: PTEN loss contributes to erlotinib resistance in EGFR-mutant lung cancer by activation of Akt and EGFR. Cancer Res 69: 3256-3261, 2009.

23. El-Sayed IH, Huang X and El-Sayed MA: Surface plasmon resonance scattering and absorption of anti-EGFR antibody conjugated gold nanoparticles in cancer diagnostics: Applications in oral cancer. Nano Lett 5: 829-834, 2005.

24. Yang L, Mao H, Wang YA, Cao Z, Peng X, Wang X, Duan H, $\mathrm{Ni}$ C, Yuan Q, Adams G, et al: Single chain epidermal growth factor receptor antibody conjugated nanoparticles for in vivo tumor targeting and imaging. Small 5: 235-243, 2009.
25. Cushing BL, Kolesnichenko VL and O'Connor CJ: Recent advances in the liquid-phase syntheses of inorganic nanoparticles. Chem Rev 104: 3893-3946, 2004.

26. Allen TM: Ligand-targeted therapeutics in anticancer therapy. Nat Rev Cancer 2: 750-763, 2002.

27. Auffan M, Rose J, Bottero JY, Lowry GV, Jolivet JP and Wiesner MR: Towards a definition of inorganic nanoparticles from an environmental, health and safety perspective. Nat Nanotechnol 4: 634-641, 2009. 